\title{
No beneficial fitness effects of random peptides
}

Michael Knopp, 1

Dan I. Andersson, 1 四

Email Dan.Andersson@imbim.uu.se

1 Department of Medical Biochemistry and Microbiology, Uppsala University, Uppsala, Sweden

To the Editor - A recent paper in Nature Ecology \& Evolution addressed whether random DNA sequences can have a beneficial effect on bacterial fitness[1]. The authors claimed that $25 \%$ of random DNA sequences cloned into an expression vector increased growth rates of Escherichia coli after performing an experiment in which a population of $E$. coli cells containing a library of highly expressed plasmid-borne random DNA sequences (each 150 nucleotides long) was serially passaged. The population of cells was sequenced at the beginning and end of the experiment to measure changes in frequency of different inserts. Increases in frequency were attributed to a positive effect on host fitness by the RNA/peptide product encoded in the random sequence. Several thousand clones were examined and $25 \%$ of the inserts were enriched, suggesting a beneficial effect on fitness.

AQ1

$\mathrm{AQ2}$

The chosen experimental set-up is problematic, as was discussed by Weisman and Eddy[2]. First, with this approach the frequency of a random sequence competing with all other random sequences in a population will depend on its relative fitness. Thus, enrichment of a sequence does not necessarily mean that it is beneficial to the bacterial cell, rather it could increase in frequency because it is less deleterious than other sequences. Second, the expression vector used has strong transcription-translation signals and will produce an RNA of approximately 190 nucleotides encoding a peptide of 37 amino acids. If these 
products have an inherent cost, any random DNA insert that reduces expression of the vector-borne RNA/peptide would seem beneficial.

$\mathrm{AQ3}$

To address this latter possibility, we experimentally tested several predictions. First, it is predicted that expression from the Ptac promoter in the expression vector is costly. We measured fitness of bacteria grown in the absence and presence of isopropylthiogalactoside (IPTG; inducer of Ptac). As shown in Table 1, the exponential growth rate of $E$. coli was reduced $12 \%$ when induced compared with non-induced. Second, it is expected that removal of either the promoter or ribosomal binding site, or the introduction of a transcription terminator upstream of the cloning site reduces the cost of expression. This was observed both during exponential growth and in competition experiments. Third, introduction of the random DNA sequences into the cloning vector should increase the relative fitness to the same extent as an expression-deficient plasmid variant. This was observed for clones 4 and 32, whereas for clone 600 no increase in fitness at all was observed (Table 1).

\section{Table 1}

Characterization of the variants of pFLAG-CTC used to determine the inherent cost of vector expression

AQ6

\begin{tabular}{|c|c|c|c|c|}
\hline $\begin{array}{l}\text { Variant } \\
\text { name }\end{array}$ & Schematic view & \multicolumn{2}{|c|}{$\begin{array}{c}\text { Relative } \\
\text { growth rate }\end{array}$} & $\begin{array}{c}\text { Selection } \\
\text { coefficient }\end{array}$ \\
\hline \multirow{2}{*}{$\begin{array}{l}\text { pFLAG- } \\
\text { CTC } \\
\text { (control } \\
\text { vector) }\end{array}$} & $\stackrel{P}{P}$ tac RBS HindllI Sall & $\begin{array}{l}\text { No } \\
\text { IPTG }\end{array}$ & $\begin{array}{l}1.00 \\
(0.02)\end{array}$ & \multirow{2}{*}{$0(0.003)$} \\
\hline & MRL & $\begin{array}{l}1 \mathrm{mi} \\
\text { IPTG }\end{array}$ & $\begin{array}{l}0.88 \\
0.0 \Omega\end{array}$ & \\
\hline \multirow{2}{*}{$\begin{array}{l}\text { pFLAG- } \\
\text { CTC } \\
\text { (clone } \\
4 \text { ) }\end{array}$} & $\stackrel{P \text { Ptac }}{\longrightarrow}$ RBS HindllI $\quad$ Sall & $\begin{array}{l}\text { No } \\
\text { IPTG }\end{array}$ & $\begin{array}{l}0.97 \\
(0.01)\end{array}$ & \multirow{2}{*}{$\begin{array}{l}0.13 \\
(0.030)\end{array}$} \\
\hline & 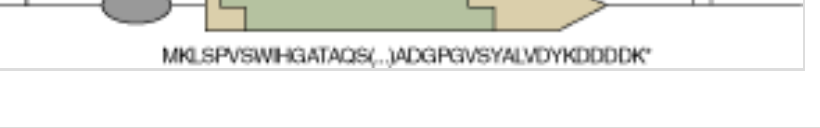 & $\begin{array}{l}1 \mathrm{mM} \\
\text { IPTG }\end{array}$ & $\begin{array}{l}0.91 \\
(0.04)\end{array}$ & \\
\hline \multirow{2}{*}{$\begin{array}{l}\text { pFLAG- } \\
\text { CTC } \\
\text { (clone } \\
32 \text { ) }\end{array}$} & $\stackrel{\text { Ptac }}{\longrightarrow}$ RBS HindllI & $\begin{array}{l}\text { No } \\
\text { IPTG }\end{array}$ & $\begin{array}{l}0.98 \\
(0.01)\end{array}$ & \multirow{2}{*}{$\begin{array}{l}0.12 \\
(0.009)\end{array}$} \\
\hline & 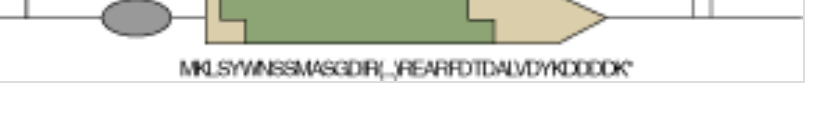 & $\begin{array}{l}1 \mathrm{mM} \\
\mathrm{IPTG}\end{array}$ & $\begin{array}{l}0.92 \\
(0.03)\end{array}$ & \\
\hline
\end{tabular}




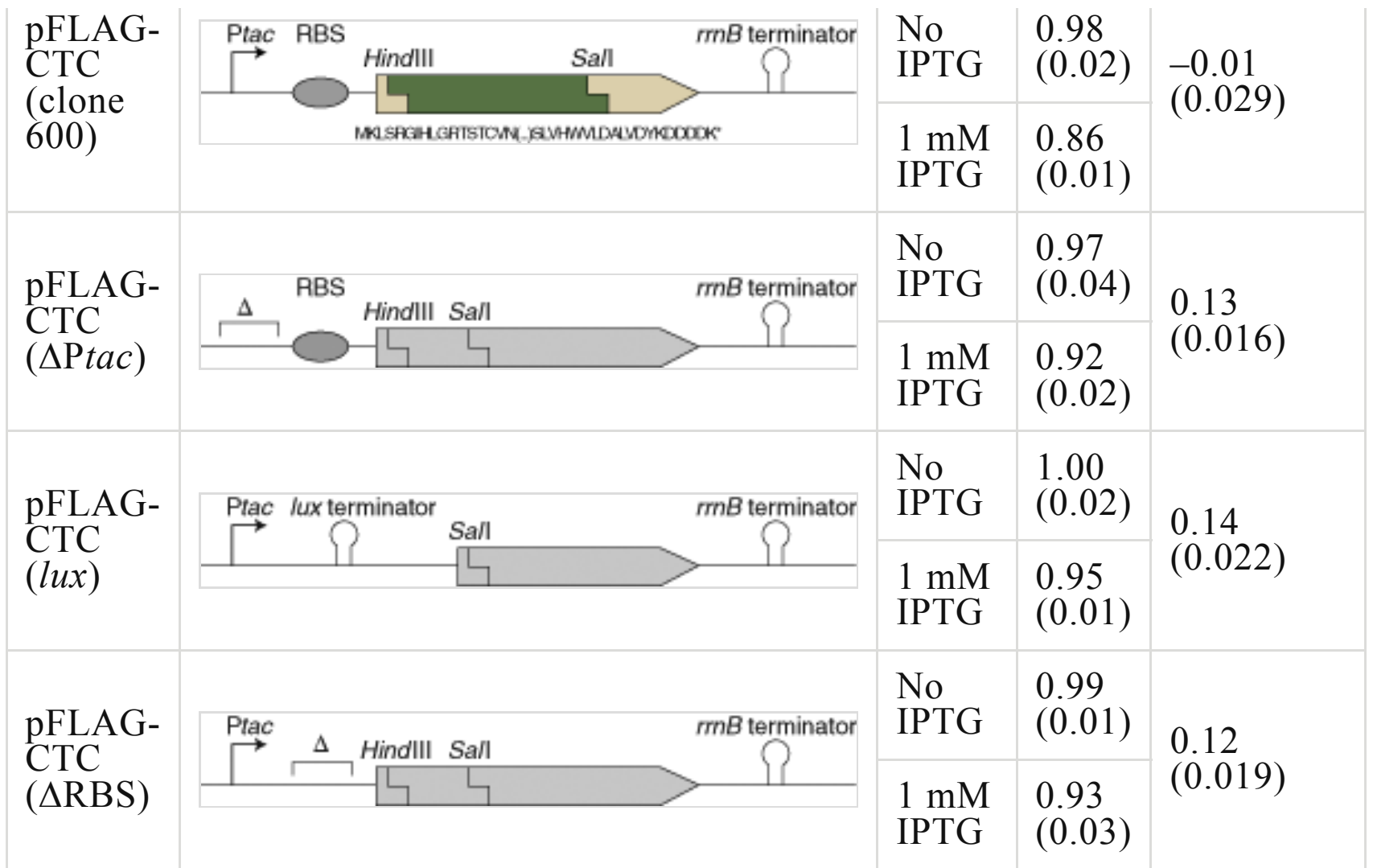

The schematic view illustrates the modification in the cloning site of the control vector in each variant. Exponential growth rates were determined from three biological and two technical replicates, and are relative to a strain carrying the control vector in the absence of IPTG (Supplementary Fig. 1). Selection coefficients were determined in competition experiments between bacteria carrying the control vector and each mutant variant under conditions similar to those used by Neme et al.[1] (Supplementary Fig. 2). The values are averages of eight biological replicates. Standard deviations are indicated in brackets.

These experiments demonstrate that expression of the vector is costly and that the apparently beneficial DNA sequences (clones 4 and 32) reduce this cost, whereas clone 600 has no beneficial effect in our experiments. Consequently, any random DNA sequence that reduces the cost of vector expression will increase in frequency in a population of competing clones and seem beneficial. In support of our hypothesis, all clones analysed by Neme et al.[1] showed a strongly reduced protein expression relative to the population average. How these random DNA sequences might act to reduce expression is unclear, but any sequence reducing RNA stability or translation of the alien protein could potentially be selected. For example, the beneficial insert in clone 4 contains the sequence TCTCCT, which is complementary to the Shine-Dalgarno sequence 
(AGGAGA) in the expression vector, and interactions between these sequences could sequester the ribosomal binding site (RBS) and reduce translation initiation.

AQ7

These experiments suggest that two of the studied DNA sequences (clones 4 and 32) owe their attributed beneficial action to unintended effects on the fitness by reducing expression of a costly synthetic peptide encoded in the control vector, whereas one (clone 600) has no beneficial effect at all. Despite our reservations about the reported results, it is important to point out that there is convincing comparative genomics support for the occurrence of de novo generation of novel functions from random DNA sequences in a number of different organisms $[3,4,5,6]$.

Electronic supplementary material

Supplementary information is available for this paper at https://doi.org/10.1038/s41559-018-0585-4.

Competing interests The authors declare no competing interests.

\section{Supplementary Information}

Supplementary Information

\section{References}

1. Neme, R., Amador, C., Yildirim, B., McConnell, E. \& Tautz, D. Nat. Ecol. Evol. 1, 0217 (2017).

2. Weisman, C. M. \& Eddy, S. R. Curr. Biol. 27, R661-R663 (2017).

3. Carvunis, A. R. et al. Nature 487, 370-374 (2012).

4. Domazet-Loso, T. \& Tautz, D. Genome Res. 13, 2213-2219 (2003). 
5. Heinen, T. J., Staubach, F., Haming, D. \& Tautz, D. Curr. Biol. 19, 15271531 (2009).

6. Tautz, D. \& Domazet-Loso, T. Nat. Rev. Genet. 12, 692-702 (2011). 